\title{
Numerical host plant relationships of Bemisia tabaci MEAMI (Hemiptera: Aleyrodidae) within and among major Australian field crops
}

\author{
Richard V Sequeira* (D) and David J Reid \\ Department of Agriculture and Fisheries, Agri-Science Queensland, Emerald, Queensland, Australia.
}

\begin{abstract}
The within-plant, vertical (internodal) distribution of the silverleaf whitefly (SLW), Bemisia tabaci (Gennadius) MEAM1 (biotype B) adult, large nymph (3rd and 4th instar) and egg stages was quantified in relation to four major Australian field crops, viz., cotton, mungbean, soybean and sunflower in 2003. The objective was to identify suitable sampling locations within the crop canopy. Ovipositional preference of SLW among the four crops under field conditions was also determined to gauge potential susceptibility and support crop choice and configuration decisions in multi-crop systems. SLW abundance at main stem leaf nodes within each crop was characterised in a twostage analysis of the proportion of infested nodes and the number of SLW at the node if infested. The vertical distribution profiles of adults and nymphs from the experimental plots were validated for cotton using scouting data collected in the 2002-2003 growing season and for mungbean from an agronomic comparison of commercial germplasm conducted in 2003. Vertical distributions of adults and juvenile stages differed among the four crops. Based on their distribution profiles, the optimal sampling locations in cotton, mungbean, soybean and sunflower are leaf nodes 3-5, 2-3, 3-4 and 5-7 for adult SLW and 7-10, 4-5, 5-6 and 17-21 for large nymphs, respectively. A comparison of egg density per unit area of green leaf among the four host plant species indicated that soybean is the most attractive to ovipositing females, mungbean the least, and cotton and sunflower intermediate. The potential of each crop as a source for SLW on the basis of nymph abundance is discussed. Low preference combined with a low source potential makes mungbean the crop of choice in broad acre cropping areas in which SLW is endemic.
\end{abstract}

Key words distribution, field crops, sampling, whitefly.

\section{INTRODUCTION}

An outbreak of Bemisia tabaci MEAM1 (B-biotype), the silverleaf whitefly (SLW), in late 2001 marked the entry of a globally feared and highly destructive insect (Gerling \& Mayer 1996; Oliveira et al. 2001; Inbar \& Gerling 2008; De Barro et al. 2011) into the pest spectrum of field crops in central Queensland, Australia (Gunning et al. 1995; Moore et al. 2004; De Barro \& Coombs 2009). Widespread damage or, in severe cases, complete crop loss was reported in grain legume, oilseed, fibre and melon crops. Irrigated cotton was deemed to be at the highest risk of long-term economic damage resulting from fibre contamination and the potential loss of overseas markets, as evident from precedents in Arizona (USA) in the 1990s (Ellsworth \& Martinez-Carrillo 2001).

The development of management strategies, including sampling plans, for invasive crop pests such as SLW entering a new country requires a thorough understanding of their agroecology in the new environment (De Barro 1995; Naranjo 1996). The agroecology of SLW has been well studied in crops and cropping systems outside Australia. Within-plant distributions of B. tabaci have been quantified in crops including cotton (Rao et al. 1991; Naranjo \& Flint 1994, 1995), cucumber (Hou et al. 2007), melons (Tonhasca et al. 1994), peanut (Lynch \& Simmons 1993) and tomato (Schuster 1998; Muniz et al. 2002; Arnó et al. 2006). Host plant preferences of $B$. tabaci and host quality for juvenile development have been the subjects of several comprehensive reviews (De Barro 1995; Gerling \& Mayer 1996; Inbar \& Gerling 2008).

The agroecology of SLW in Australian cropping systems was a crucial knowledge gap at the time of the outbreak in central Queensland. The SLW outbreak provided the impetus for the development of a comprehensive SLW management R\&D program for the cotton and grains industries in central Queensland from 2002 to 2006. A key component of the $R \& D$ program involved characterisation of agro-ecological parameters, including temporal, spatial and within-plant distributions, host plant preferences and plant-mediated mortality factors.

In this paper, we report on activities conducted during the 2002-2003 cotton season (September-April) within the SLW R\&D program to quantify host plant relationships in four major Australian field crops, viz., cotton, mungbean, soybean and sunflower. We report firstly on experimental assessments of within-plant vertical distributions of adult and juvenile SLW in each of the four crops at two times. The objective of this study was to generate base-line distributional data and identify potential sampling planes and locations (nodes) within the crop canopy to support future development of

*richard.sequeira@daf.qld.gov.au

This work is copyright. Apart from any use as permitted under the Copyright Act 1968, no part may be reproduced without prior written permission. Requests and enquiries concerning reproduction and rights should be directed in the first instance to John Wiley \& Sons Ltd of The Atrium, Southern Gate, Chichester, West Sussex PO19 8SQ United Kingdom. Alternately, queries can be directed to the Department of Agriculture and Fisheries, 41 George Street, Brisbane QLD. 4000 Australia 
crop-specific sampling plans. Next, we test the validity of recommended sampling locations inferred from the experimental assessment using scouting data collected in two commercial cotton crops and an agronomic comparison of commercial mungbean germplasm. Finally, we report on asymmetries in egg and nymph abundance among the four crops as a measure of host plant preference and population recruitment potential, respectively. We discuss the results in the context of SLW host plant preferences, crop choice and the potential for population recruitment in mixed cropping systems.

\section{MATERIALS AND METHODS}

\section{Experimental assessment}

The study was conducted at the Queensland Department of Agriculture and Fisheries research facility at Emerald $\left(23^{\circ} 34^{\prime} \mathrm{S}, 148^{\circ} 10^{\prime} \mathrm{E}\right)$. The experimental design compared SLW distribution and oviposition responses to four 'monoculture' and one 'interplant' crop layouts (treatments) in field plots of dimension $8 \mathrm{~m}$ wide $\times 5 \mathrm{~m}$ long in a randomised block design with three replicates. Each monoculture treatment consisted of eight rows (1 m spacing) of either cotton (Gossypium hirsutum L cv 'Delta Topaz'), mungbean (Vigna radiata (L.) R Wilczek cv 'Emerald'), soybean (Glycine $\max (\mathrm{L}$.) Merr cv 'Jabiru') or sunflower (Helianthus annuus L cv 'Advantage'). The interplant treatment consisted of three rows of soybean planted in the furrow between eight rows (1 $\mathrm{m}$ spacing) of cotton such that a row of soybean was interspersed between cotton rows 2 and 3, 4 and 5, and 6 and 7. In the interplant treatment, the rows of soybean and rows of cotton were treated as subplots. Plots within blocks were separated by $2 \mathrm{~m}$ bare earth buffers.

The inclusion of monoculture and interplant treatments within the experimental layout was designed to test whether or not innate oviposition preference for host plant species, i.e. rank order of host plant preference, as indexed by the asymmetry in SLW egg distribution among crops, was influenced by differences in the availability of green leaf area for oviposition and physical proximity under field conditions.

The four crops were planted using standard commercial sowing rates on 22 January 2003. A common planting date for all crops was justified by the overriding need to facilitate equal availability of all species for colonisation by SLW so as to enable valid comparisons among them. For mungbean, soybean and sunflower, the planting date was well within the optimal planting window (December-January) for commercial crops in central Queensland. For cotton, the planting date was outside the preferred window for commercial cropping (August-October) but well within the window in which the diurnal temperature regime and light intensity were sufficient to produce vegetative growth and biomass that was similar to earlier planted crops ( $\mathrm{R}$ Sequeira, unpublished data).

The monoculture plots were sampled at 36 days (Time 1) and 63 days (Time 2) after planting; the interplant plots were sampled only at Time 2 . The potential for further sampling was limited by the short time-to-maturity of mungbean (70-90 days) and sunflower (70-80 days).

\section{Sampling}

Time 1. The distribution of SLW adults and nymphs (3rd and 4th instars, including the red-eye stage) on whole leaves along the main stem of each crop was quantified using the leaf turn method and visual counts (Naranjo \& Flint 1994; Arnó et al. 2006). Beginning at the first fully unfurled leaf at the growing terminal (node 1), adults were counted on a single leaf (the middle leaflet of a trifoliate leaf on the legume species) per plant so as to minimise disturbance. In this manner, a total of 20 leaves (10 in replicate 1 and five in each of replicates 2 and 3) were sampled at each leaf node position across all plots within plant species. Foliage on all branches coming off the main stem was ignored. Sampling was restricted to the monoculture plots so as to exclude any potential impacts of cotton/soybean interplanting on insect abundance and distribution in the interplant plots.

Preliminary attempts to estimate nymph abundance under field conditions based on visual counting using the leaf turn method proved impractical, particularly given the difficulty in distinguishing with the naked eye between nymphs that were healthy and those that had been parasitised or predated upon. For this reason, healthy nymphs were counted on the abaxial side of excised whole main stem leaves (all leaflets of trifoliate legume leaves) at every node on a total of 20 randomly selected whole plants (10 from replicate 1 and five from each of replicates 2 and 3 ) within plant species using a hand lens in the laboratory.

Time 2. A modified sampling protocol was necessary due to increased plant size, number of nodes and SLW abundance in all crops relative to Time 1 . For logistical reasons, sampling at every alternate node was deemed a reasonable alternative to sampling at every node on every plant. Estimation of adult densities using the leaf turn method was impractical due to their propensity for flight when disturbed. Therefore, the distribution of SLW eggs (white + brown) at nodes along the main stem was used as proxy for the distribution of adults. Furthermore, population growth made counting of juvenile stages on whole leaves impractical. Therefore, egg and nymph densities were enumerated within a $3.88 \mathrm{~cm}^{2}$ disk area (Naranjo \& Flint 1994, 1995) on the abaxial surface of the node leaf (the middle leaflet of trifoliate legume leaves) at alternate nodes of 10 plants per plot (or subplot for interplant treatment).

\section{Commercial cotton}

The scouting data originated from two approximately 25 ha blocks (Blocks 1 and 2, hereafter) of commercial cotton from the eastern and western part of the Emerald irrigation area, respectively. Block 1 was planted to variety 'Sicot 71' on 5 October 2002 and sampled for SLW on 6 December 2002, (62 days after planting). Block 2 was planted to variety ' $\mathrm{Nu}$-Pearl Roundup Ready' on 13 September 2002 and sampled for SLW on 5 December 2002 (83 days after planting). Both blocks were planted on a $1 \mathrm{~m}$ row spacing with recommended inputs and planting parameters for commercial cotton.

Within each block, the number of adults and nymphs on main stem leaves at nodal positions 3-10 within a randomly selected 
plant were counted. This procedure was repeated for four groups of 10 plants. Adults were counted using the leaf turn method; nymphs were counted on excised whole leaves using a hand lens.

\section{Mungbean validation plots}

Five mungbean cultivars ('White Gold', 'Emerald', 'Delta', 'Green Diamond' and 'Berken') were planted on 30 January 2003 in field plots of dimension $10 \mathrm{~m}$ long $\times 8 \mathrm{~m}$ wide with a $1 \mathrm{~m}$ row spacing in a randomised block design with three replicates as part of an agronomic comparison of commercial germplasm conducted at the Queensland Department of Agriculture and Fisheries research facility at Emerald. Within each field plot, three plants were selected at random and the number of SLW adults, and nymphs on main stem leaves at nodal positions 1-6 were counted on 10 March 2003, 39 days after planting. Adults were counted using the leaf turn method; nymphs were counted on excised whole leaves using a magnifying glass. A total of nine plants were sampled for each cultivar.

\section{Data analysis}

\section{SLW within-plant distributions}

The vertical distribution of SLW among main stem leaf nodes within each crop was characterised by a two-stage analysis: the proportion of infested nodes and the density (counts) of SLW if infested. The leaf at each node was classified as either 'infested' and given a score of 1 or 'not infested' and given a score of 0 , based on whether or not the density on that leaf was equal to or exceeded a tally threshold: $\geq 1$ per leaf (TT1) or $\geq 2$ per leaf (TT2). The rationale for using different tally thresholds was to compare the level of resolution provided by the two methods with respect to differences in density among leaf nodes. Time 1 data from the experimental assessment were restricted to nodes above (and including) 8, 6, 7 and 16 for cotton, mungbean, soybean and sunflower, respectively, thereby excluding the lowermost nodes with mostly zero counts. Similarly, Time 2 data were restricted to nodes above (and including) 11, 11, 11 and 27 for cotton, mungbean, soybean and sunflower, respectively.

The infestation level at each node location for each SLW stage, defined as the proportion of leaves infested with that stage, for both tally thresholds, was modelled as a generalised linear mixed model with a binomial error structure and logit link function. The density of each SLW stage on infested leaves, for TT1 and TT2, was then modelled as a generalised linear mixed model with either a Poisson or negative binomial error distribution and corresponding log or log-ratio link function. Models included the random effects of blocks and plants and the fixed effect of node number.

Preliminary analyses including a covariance structure on nodes to account for possible correlation among nodes were performed on Time 1 data with a tally threshold of 1 . The appropriateness of the covariance structure was assessed by the Akaike and Bayesian information coefficients. There was no evidence of correlation among nodes for infestation level of adults for all four crops while there was evidence of correlation among nodes for nymphs in cotton and soybean, but not for mungbean, while models for nymphs in sunflower did not converge. Given the lack of strong and consistent evidence of correlation among nodes and that results were similar regardless of the inclusion of the correlation structure, we decided to use the simpler model without the correlation structure for all analyses. From these models, estimates of the level of infestation $(\hat{p})$ and the number if infested $(\hat{n})$ were obtained. Pairwise differences in $\hat{p}$ and $\hat{n}$ among node locations were tested using a protected LSD procedure at $P=0.05$. All analyses were performed using GENSTAT 13th Edition (VSN International 2010).

\section{Host plant species preference}

The rank order of crops with respect to ovipositional preference was determined by comparing the density of eggs and nymphs among plant species in monoculture and interplant treatments from the experimental assessment data collected at Time 2. To facilitate meaningful comparisons of unit abundance among crops differing in growth habit, architecture and other phenological characteristics, the leaf area index (LAI), defined as the amount of green leaf per unit area of cultivation (Ross 1981; Chen \& Black 1991), was estimated using the Agricultural Production Systems Simulator (APSIM model; Keating et al. 2003). Standard (commercial) agronomic parameter inputs for each crop and a planting date of 22 January 2003 were used. Densities of eggs and nymphs (number.cm ${ }^{-2}$.plant ${ }^{-1}$ ) for a given crop were then multiplied by its LAI. The LAI-weighted egg densities were log-transformed, and nymph densities were 4th root transformed prior to analysis with restricted maximum likelihood (REML) with random effects of plots, sub-plots and plants and the fixed effect of crop. The component crops within the intercropped treatment were assigned unique crop identification codes.

\section{RESULTS}

\section{Within-plant distributions}

\section{Experimental cotton}

Estimates of infestation level for adult SLW at Time 1 for TT1 were generally low; $\hat{p}_{\text {ADULTS(I) }}$ was less than $25 \%$ (Fig. 1a) and not significantly different $(P>0.05)$ among main stem leaf nodes. Corresponding estimates for TT2 were too low to be computed accurately. Estimates of adult density on infested leaves $\left(\hat{n}_{\text {ADULTS(1) }}\right)$ were generally less than 2 . leaf $^{-1}$ for TT1 (Fig. 1a) confirming the low abundance of adults on cotton.

The infestation level for nymphs on whole leaves at Time $1\left(\hat{p}_{\text {NYMPHS }(1)}\right)$ based on TT1 varied significantly $(P<0.05)$ among nodes, being higher in the lower half of the plant canopy (Fig. 1b), while estimates based on TT2 did not differ $(P>0.05)$ among nodes. $\hat{n}_{\text {NYMPHS(1) }}$ at Time 1 varied significantly $(P<0.05)$ among leaf nodes for both tally thresholds.

(C) State of Queensland (Department of Agriculture and Fisheries) 2017 

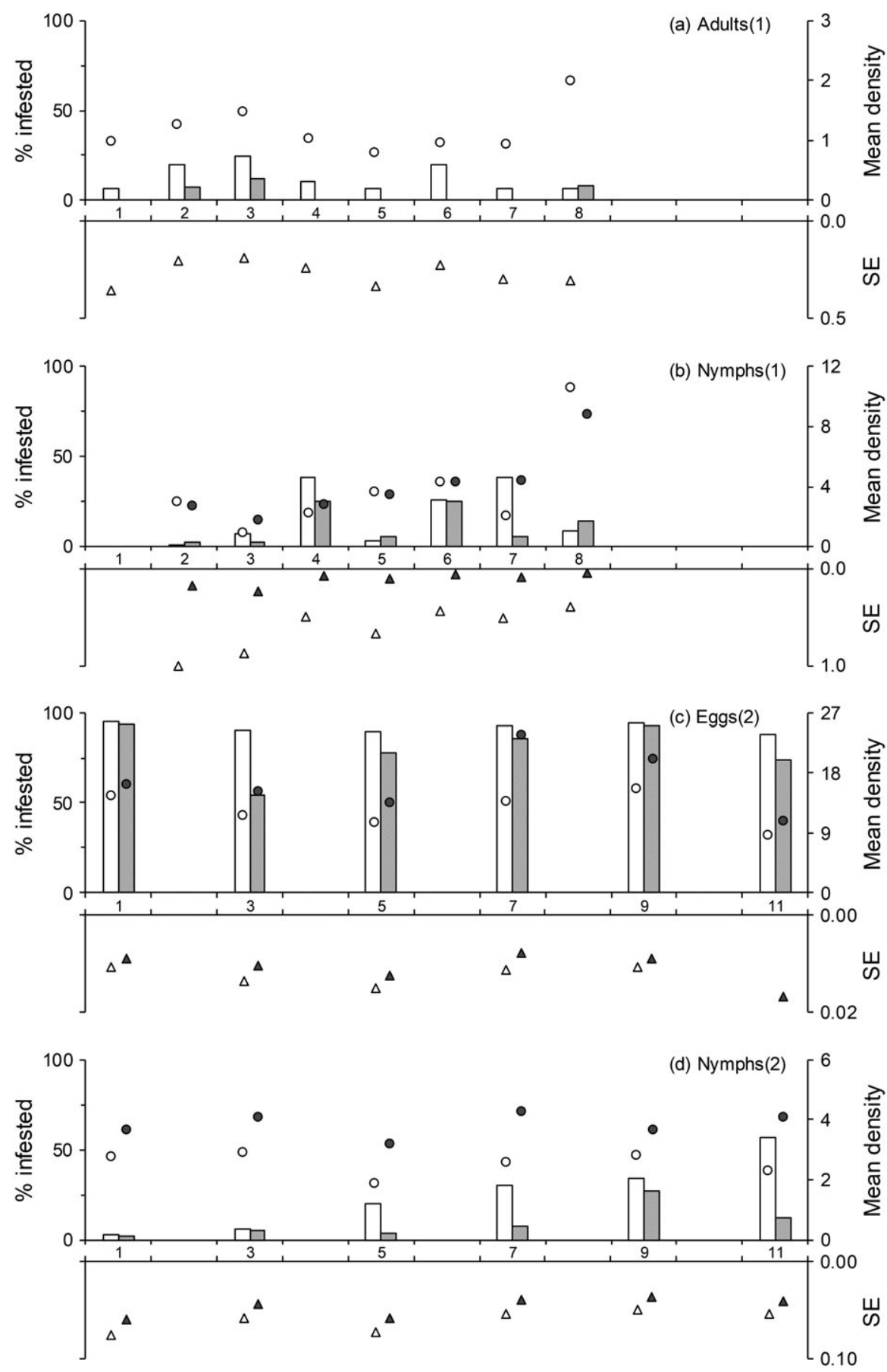

Mainstem node number

Fig. 1. Predicted infestation level of silverleaf whitefly adults, nymphs and eggs on cotton expressed as the percentage of infested main stem leaves (\% infested) and the corresponding density on infested leaves for: (a) adults at Time 1, (b) nymphs at Time 1, (c) eggs at Time 2 and (d) nymphs at Time 2 . Infestation level was calculated using tally thresholds of $\geq 1$ (TT1, open bars) and $\geq 2$ (TT2, hatched bars) individuals per sampling unit. Density is represented by open circles (TT1) and filled circles (TT2). Estimated standard error (SE) of the mean (transformed scale) is represented by open triangles (TT1) and filled triangles (TT2).

At Time 2, infestation levels for SLW eggs within the leaf disk area based on TT1 were generally high (>75\%); $\hat{p}_{E G G S(2)}$ and $\hat{n}_{E G G S(2)}$ were not significantly different $(P>0.05)$ among leaf nodes (Fig. 1c). By comparison, for TT2, $\hat{p}_{E G G S(2)}$ was highest $(P<0.05)$ on nodes 1,7 and 9 and $\hat{n}_{E G G S(2)}$ highest $(P<0.05)$ on nodes 7 and 9 .
Estimates of the infestation level of nymphs at Time 2 $\left(\hat{p}_{\text {NYMPHS(2) }}\right)$ varied significantly $(P<0.01)$ among nodes for both tally thresholds, increasing as node number increased, whereas the corresponding density estimates $\left(\hat{n}_{N Y M P H S(2)}\right)$ were not significantly different $(P>0.05)$ among leaf nodes for either tally threshold (Fig. 1d). 


\section{Commercial cotton}

Estimates of infestation level for adult SLW on commercial cotton $\left(\hat{p}_{\text {ADULTS(cc) }}\right)$ for TT1 ranged from 5 to $30 \%$ in Block 1 (Fig. 2a), and 17 to $35 \%$ in Block 2 (Fig. 2c) but did not differ significantly $(P>0.05)$ among main stem leaf nodes for either block. Corresponding estimates for TT2 could not be computed for Block 1 due to low abundance or zero counts; infestation level was not significantly different $(P>0.05)$ among main stem leaf nodes for Block 2.
The estimated density of adults on infested leaves $\left(\hat{n}_{\text {ADULTS }(c c)}\right)$ differed $(P<0.05)$ among leaf nodes for TT1 in both blocks, being greatest for nodes 6 (1.5 adults.leaf $\left.{ }^{-1}\right)$ and 5 (2.1 adults.leaf $^{-1}$ ) for Blocks 1 (Fig. 2a) and 2 (Fig. 2c), respectively. Estimates for TT2 in Block 2 ranged from 1.8 to 2.8 adults.leaf ${ }^{-1}$ and did not differ $(P>0.05)$ among leaf nodes.

The infestation level for nymphs $\left(\hat{p}_{N Y M P H S(c c)}\right)$ for both tally thresholds in Block 1 was skewed to the left increasing $(P<0.01)$ with node number, being greatest for nodes 9 and
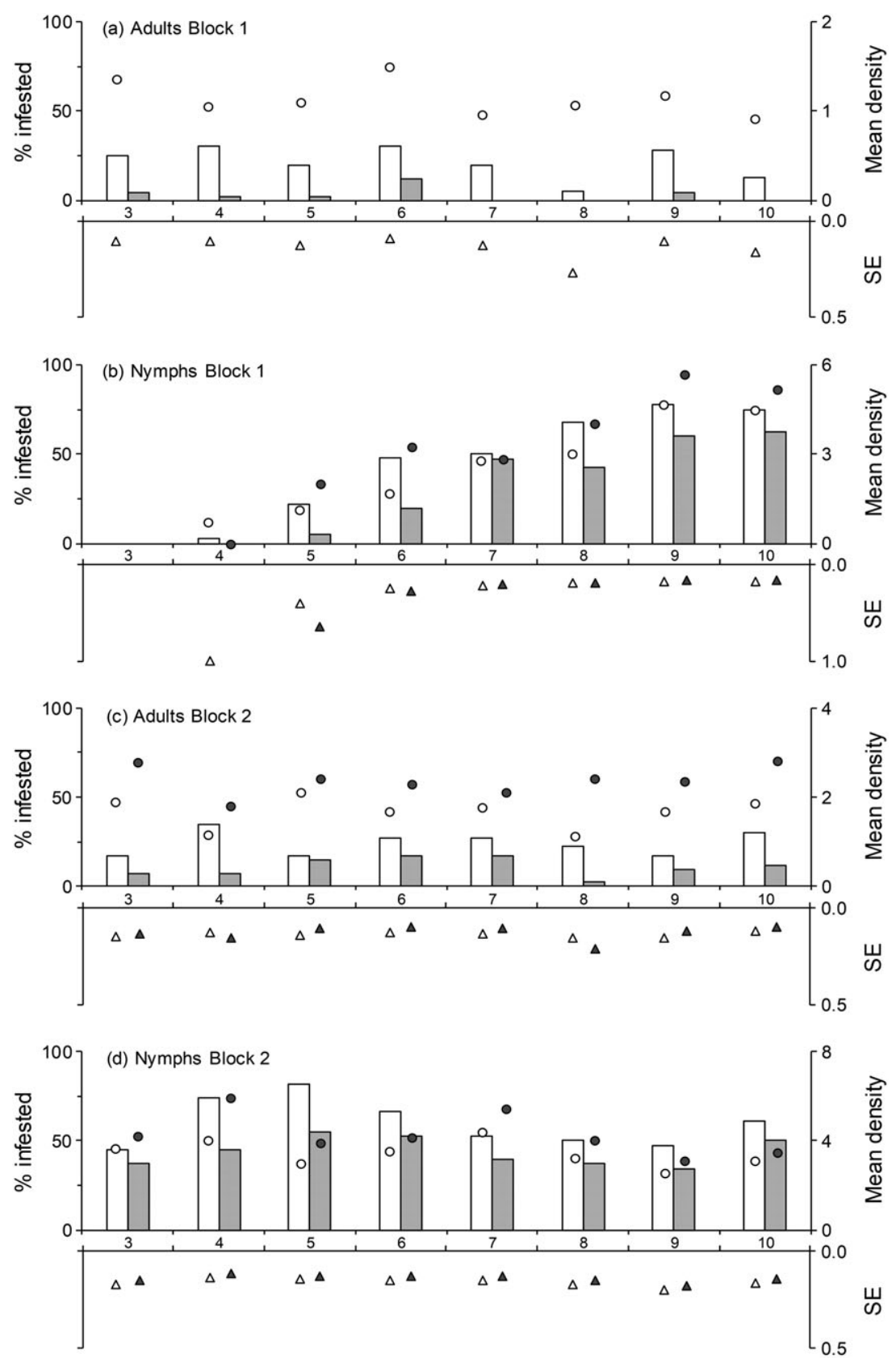

Mainstem node number

Fig. 2. Predicted infestation level of silverleaf whitefly adults and nymphs in two blocks of commercial cotton expressed as the percentage of infested main stem leaves (\% infested) and the corresponding density on infested leaves for: (a) adults - Block 1, (b) nymphs - Block 1, (c) adults - Block 2 and (d) nymphs - Block 2. Infestation level was calculated using tally thresholds of $\geq 1$ (TT1, open bars) and $\geq 2$ (TT2, hatched bars) individuals per sampling unit. Density is represented by open circles (TT1) and filled circles (TT2). Estimated standard error (SE) of the mean (transformed scale) is represented by open triangles (TT1) and filled triangles (TT2). 
10 for TT1 and for nodes 7-10 for TT2 (Fig. 2b). By comparison, $\hat{p}_{N Y M P H S(c c)}$ in Block 2 was highest $(P<0.05)$ on nodes 4 and 5 for TT1 and not different $(P>0.05)$ among main stem nodes for TT2 (Fig. 2d).

Nymph density $\left(\hat{n}_{N Y M P H S(c c)}\right)$ on infested leaves in Block 1 increased $(P<0.05)$ in line with the corresponding infestation levels for both tally thresholds (Fig. 2b) being greatest for nodes 9-10 for TT1 and nodes 8-10 for TT2. In Block 2, $\hat{n}_{N Y M P H S(c c)}$ did not differ significantly $(P>0.05)$ among leaf nodes for
TT1 but did for TT2 $(P<0.05)$ being greatest for leaf node 4 (5.9 nymphs.leaf $^{-1}$; Fig. 2d).

\section{Experimental mungbean}

Infestation levels for adults at Time 1 based on TT1 and TT2 were right skewed, favouring the upper section of the plant (Fig. 3a). Values of $\hat{p}_{\text {ADULTS(1) }}$ based on TT1 were not significantly different $(P>0.05)$ among main stem leaf nodes, while
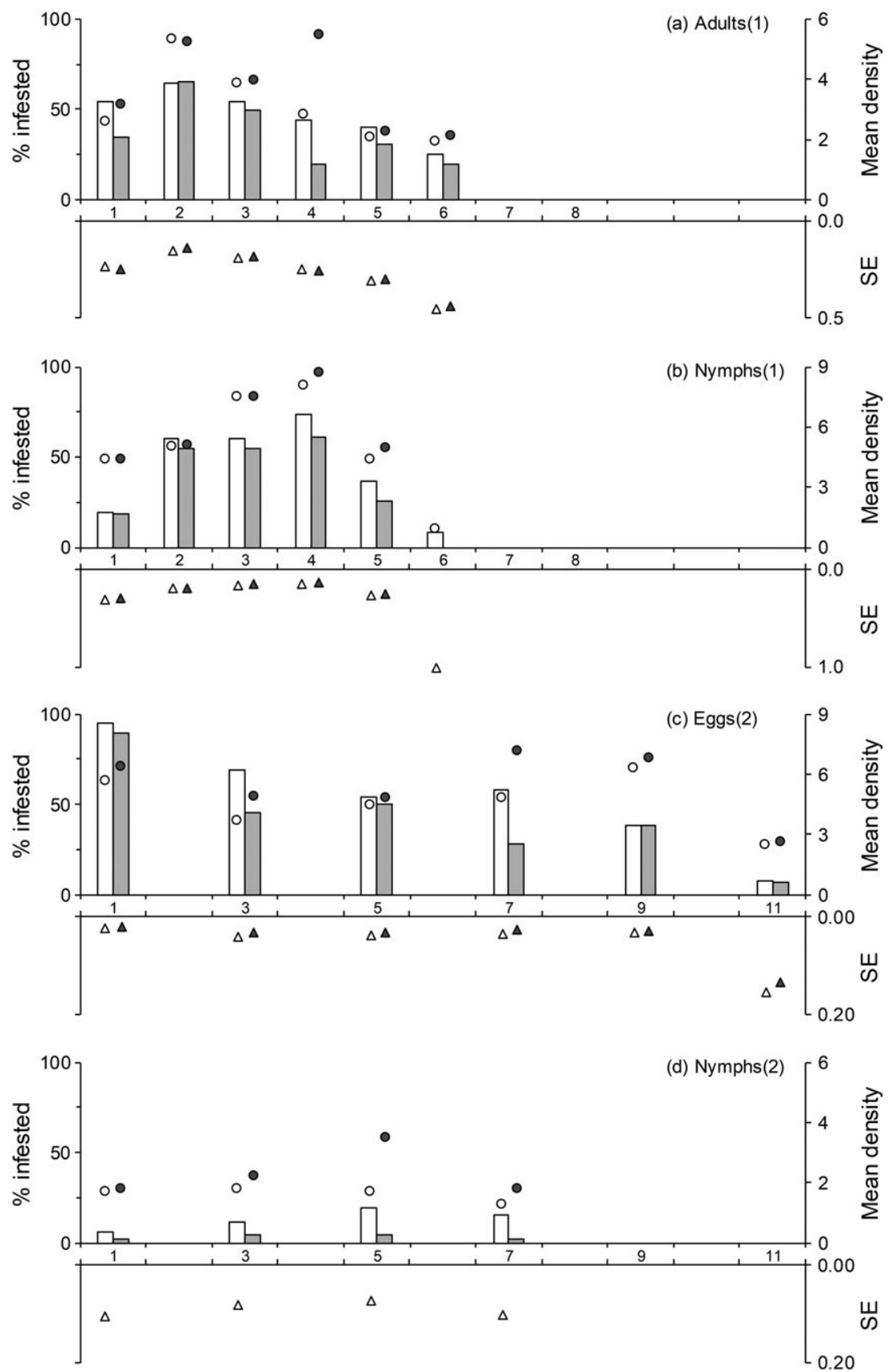

Mainstem node number

Fig. 3. Predicted infestation level of silverleaf whitefly adults, nymphs and eggs on mungbean expressed as the percentage of infested main stem leaves (\% infested) and the corresponding density on infested leaves for: (a) adults at Time 1, (b) nymphs at Time 1, (c) eggs at Time 2 and (d) nymphs at Time 2 . Infestation level was calculated using tally thresholds of $\geq 1$ (TT1, open bars) and $\geq 2$ (TT2, hatched bars) individuals per sampling unit. Density is represented by open circles (TT1) and filled circles (TT2). Estimated standard error (SE) of the mean (transformed scale) is represented by open triangles (TT1) and filled triangles (TT2). 
values of $\hat{p}_{\text {ADULTS(1) }}$ based on TT2 were significantly higher $(P<0.05)$ at nodes $1-3$ than at lower nodal positions. The distribution of $\hat{n}_{A D U L T S(1)}$ based on TT1 was clearly unimodal with the highest density $(P<0.05)$ at node 2 followed by node 3 (Fig. 3a); internodal differences were not significant for TT2.

Nymphs at Time 1 were concentrated in the middle section of the plant, with $\hat{p}_{N Y M P H S(1)}$ highest $(P<0.05)$ on nodes $2-4$ for TT1 and TT2 (Fig. 3b). $\hat{n}_{N Y M P H S(1)}$ for both tally thresholds was highest $(P<0.05)$ on node 4 .

$\hat{p}_{E G G S(2)}$ at Time 2 was highest a node $1(P<0.001)$ then decreased to a common level for nodes 3, 5 and 7 before further decreasing for lower nodes (Fig. 3c). $\hat{n}_{E G G S}$ did not differ significantly $(P>0.05)$ among leaf nodes for either tally threshold.

The infestation level and density of nymphs at Time 2 did not differ $(P>0.05)$ among leaf nodes for both tally thresholds and were extremely low as evidenced by $\hat{p}_{N Y M P H S(2)}$ mostly below $15 \%$ and $\hat{n}_{N Y M P H S(2)}$ low relative to Time 1 estimates (Fig. $3 \mathrm{~d}$ ).

\section{Mungbean validation plots}

The infestation level of adult SLW $\left(\hat{p}_{A D U L T S(m b)}\right)$ varied significantly $(P<0.001)$ among leaf nodes for both tally thresholds (Fig. 4). $\hat{p}_{\text {ADULTS(mb) }}$ was similar among nodes $1-4$ for TT1 and nodes 1-3 for TT2 but higher than lower nodes. The density on infested leaves $\left(\hat{n}_{A D U L T S(m b)}\right)$ differed $(P<0.01)$ among leaf nodes for both tally thresholds being highest at node 2 for TT1 and TT2.

\section{Experimental soybean}

There were no significant differences $(P>0.05)$ in infestation level and density estimates for adults among main stem leaf nodes for both tally thresholds at Time 1 (Fig. 5a).

The internode profile of $\hat{p}_{N Y M P H S(1)}$ for both tally thresholds was sharply skewed to the left; infestation level increased $(P<0.01)$ as node number increased reaching $100 \%$ infestation at nodes 5 and 6 (Fig. 5b). Values of $\hat{n}_{\text {NYMPHS(1) followed a }}$ similar profile for both tally thresholds, but there was only weak evidence $(P=0.052$ and $P=0.077$ for TT1 and TT2, respectively) of differences among nodes.
The profile of $\hat{p}_{E G G S(2)}$ for both tally thresholds showed close to $100 \%$ infestation at nodes $1-5$ followed by a steady decline $(P<0.001)$ in infestation level with increasing node number (Fig. 5c). The profile for $\hat{n}_{E G G S(2)}$ was similar with density being highest for nodes 1-5 and least for nodes in the lower half of the plant, although this was only tested for TT2 as the model did not converge for TT1.

The infestation level for nymphs differed $(P<0.01)$ among nodes for both tally thresholds, with $\hat{p}_{N Y M P H S(2)}$ being high ( $>75 \%$ ) for the top 7 nodes before dropping substantially by node 11 (Fig. 5d). Estimates of $\hat{n}_{N Y M P H S(2)}$ were relatively high (7-10 per node) and were not significantly different $(P>0.05)$ among leaf nodes.

\section{Experimental sunflower}

The distribution of adults at Time 1 was characterised by higher infestation levels and densities in the top half of the plant; $\hat{p}$ ADULTS(1) Was similar for leaf nodes 2-10, mostly above $90 \%$, dropping to around $50 \%$ on lower leaf nodes for both TT1 and TT2 $(P<0.05 ;$ Fig. 6a). Density estimates differed $(P<0.001)$ with leaf node, $\hat{n}_{A D U L T S(1)}$ being greatest for nodes 4-8 for both TT1 and TT2.

The infestation level for nymphs at Time 1 differed $(P<0.001)$ with leaf node, with nymphs clearly confined to the bottom half of the plant, as evidenced by the distribution of $\hat{p}_{N Y M P H S(1)}$ being skewed sharply to the left, with $\geq 70 \%$ infestation of leaf nodes 9-16 for TT1 and TT2 (Fig. 6b). $\hat{n}_{N Y M P H S(1)}$ did not differ $(P>0.05)$ among leaf nodes with TT1 but differed $(P<0.05)$ among nodes with TT2 with nodes 12 and 13 having higher densities than the other nodes.

The internode profile of $\hat{p}_{E G G S(2)}$ for both tally thresholds at Time 2 differed $(P<0.001)$ among leaf nodes, being high across leaf nodes 3-19 and less for nodes lower down the main stem (Fig. 6c). The corresponding values of $\hat{n}_{E G G S}$ were significantly higher $(P<0.001)$ at nodes $5-11$ than those above or below.

Nymphs at Time 2 were confined to below node 5. $\hat{p}_{N Y M P H S(2)}$ was significantly different $(P<0.001)$ among leaf nodes; the infestation level for both tally thresholds was generally highest

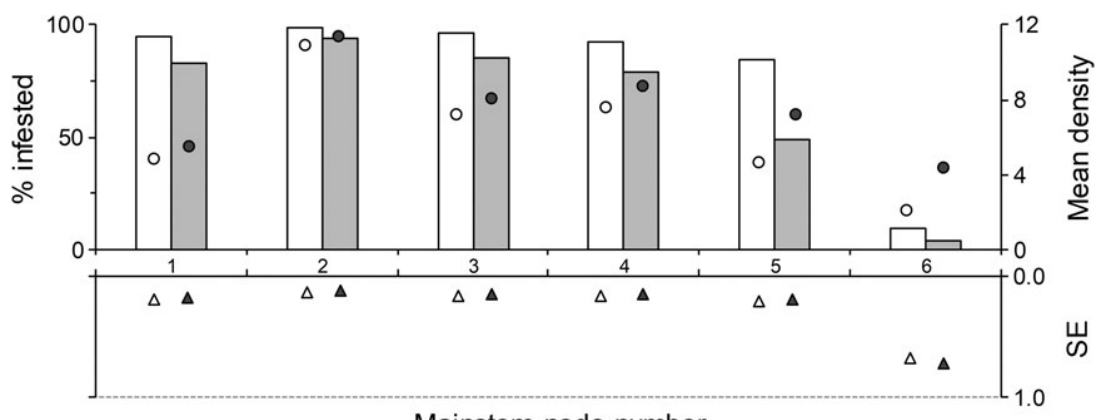

Fig. 4. Predicted infestation level of silverleaf whitefly adults in mungbean plots from an agronomic comparison of commercial germplasm in Emerald, expressed as the percentage of infested main stem leaves (\% infested) and the corresponding density on infested leaves using tally thresholds of $\geq 1$ (TT1, open bars) and $\geq 2$ (TT2, hatched bars) individuals per sampling unit. Density is represented by open circles (TT1) and filled circles (TT2). Estimated standard error (SE) of the mean (transformed scale) is represented by open triangles (TT1) and filled triangles (TT2). 

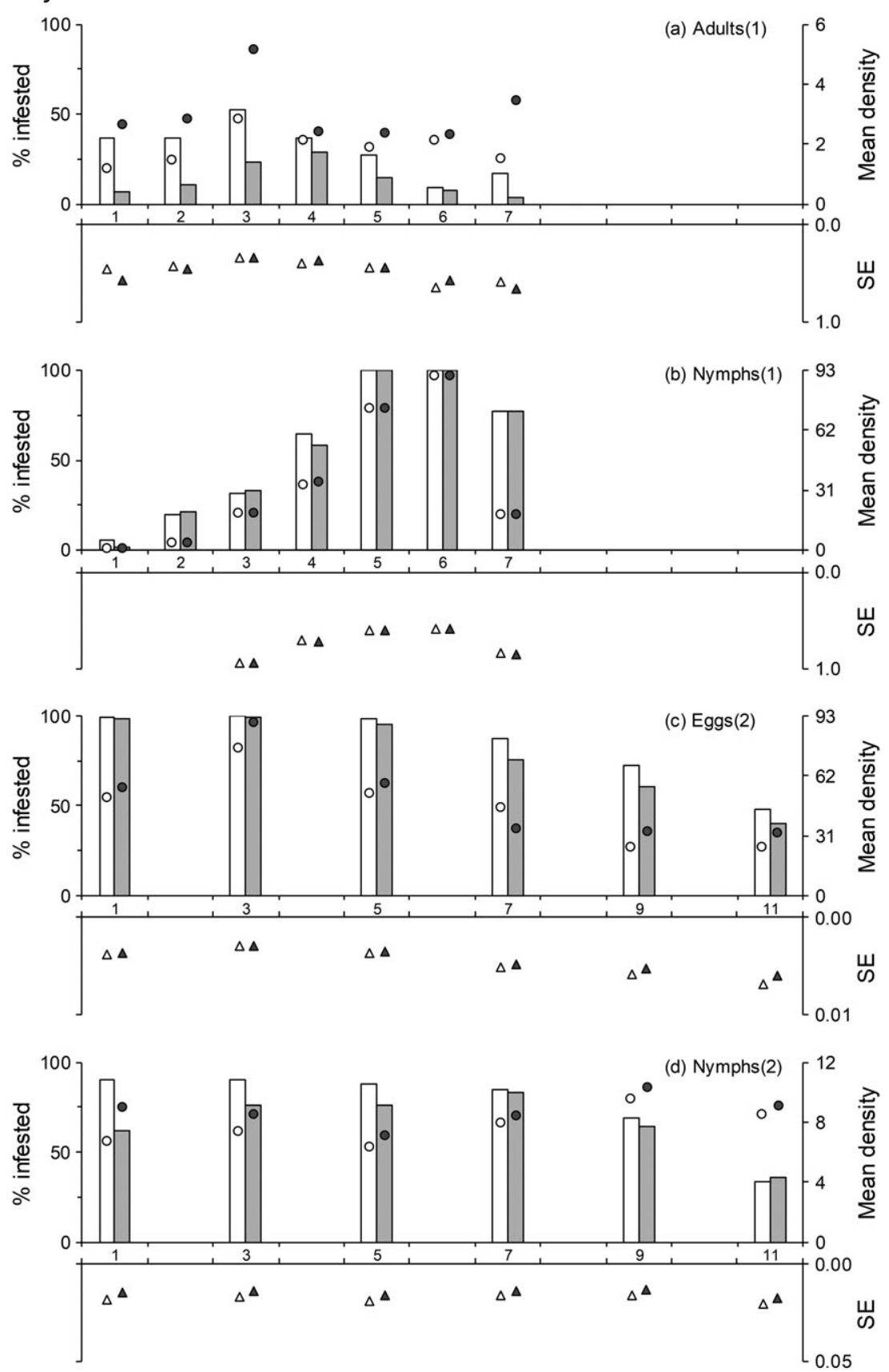

Mainstem node number

Fig. 5. Predicted infestation level of silverleaf whitefly adults, nymphs and eggs on soybean expressed as the percentage of infested main stem leaves (\% infested) and the corresponding density on infested leaves for: (a) adults at Time 1, (b) nymphs at Time 1, (c) eggs at Time 2 and (d) nymphs at Time 2 . Infestation level was calculated using tally thresholds of $\geq 1$ (TT1, open bars) and $\geq 2$ (TT2, hatched bars) individuals per sampling unit. Density is represented by open circles (TT1) and filled circles (TT2). Estimated standard error (SE) of the mean (transformed scale) is represented by open triangles (TT1) and filled triangles (TT2).

among nodes 11-25, and $\hat{n}_{N Y M P H S(2)}$ was highest for nodes 19-23 for TT1 and 19-25 for TT2 (Fig. 6d).

\section{Host plant species preference}

Although the area (plot size) in the monoculture plots was the same for all crops, sunflower had twice as much green leaf area as cotton while mungbean and soybean had 3-4 times as much as cotton (Table 1). By comparison, in the interplant treatment, soybean had 1.4 times more green leaf area than cotton. Egg densities weighted by LAI estimates (Table 1) were significantly different $(P<0.001)$ among crop treatments (Fig. 7a). Among the monoculture treatments, soybean had 11 times more eggs.cm ${ }^{-2}$ of green leaf area than the average egg density across the cotton, mungbean and sunflower plots. Within the interplanted plots, soybean in the furrow had 26 times more eggs. $\mathrm{cm}^{-2}$ of green leaf area than cotton. The egg density on cotton in the interplant plots was $68 \%$ less than that in the monoculture plots. The 

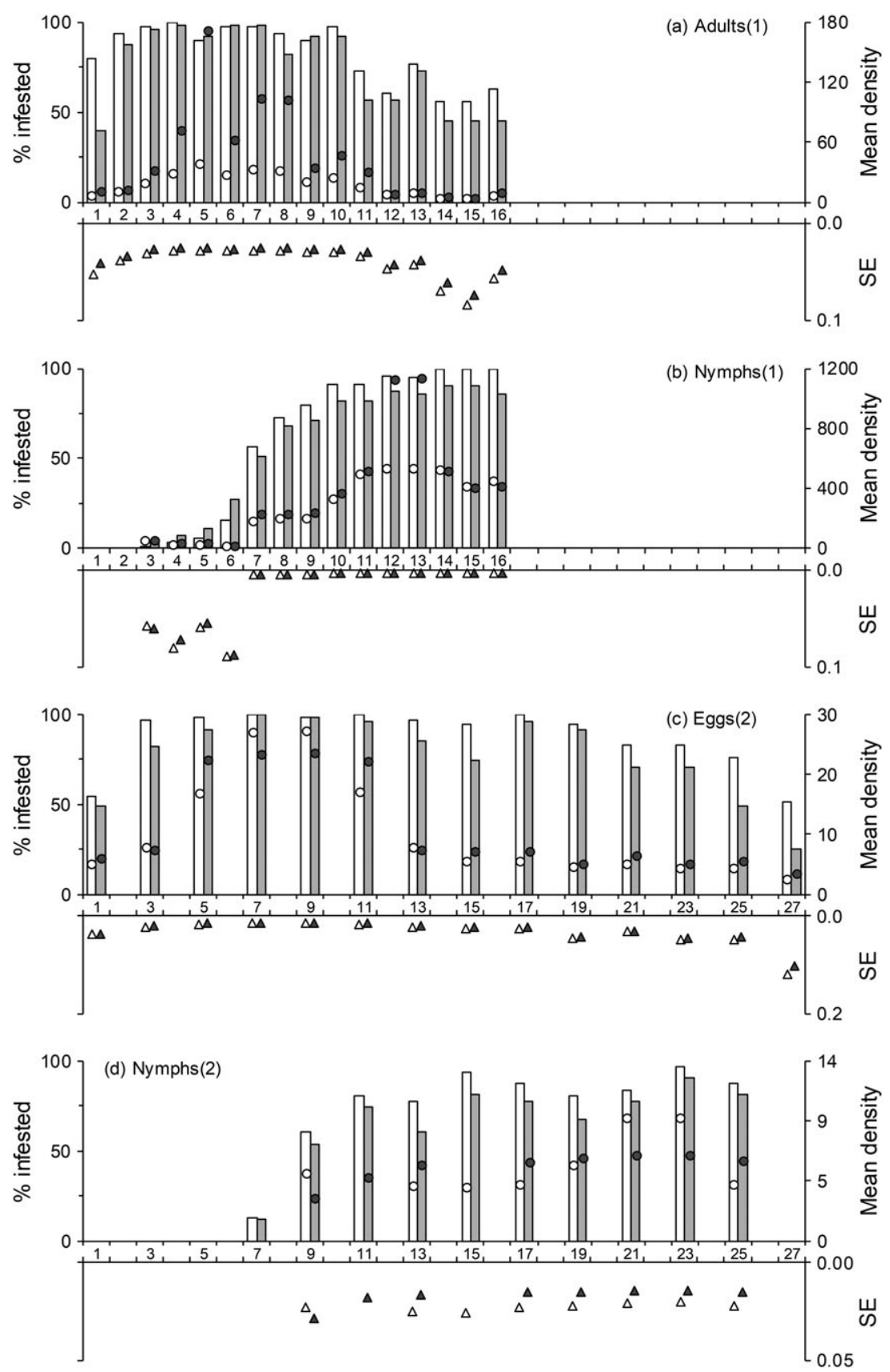

Mainstem node number

Fig. 6. Predicted infestation level of silverleaf whitefly adults, nymphs and eggs on sunflower expressed as the percentage of infested main stem leaves (\% infested) and the corresponding density on infested leaves for: (a) adults at Time 1, (b) nymphs at Time 1, (c) eggs at Time 2 and (d) nymphs at Time 2. Infestation level was calculated using tally thresholds of $\geq 1$ (TT1, open bars) and $\geq 2$ (TT2, hatched bars) individuals per sampling unit. Density is represented by open circles (TT1) and filled circles (TT2). Estimated standard error (SE) of the mean (transformed scale) is represented by open triangles (TT1) and filled triangles (TT2).

distribution of nymphs among crop treatments closely matched that of eggs, with density on soybean greater than on sunflower which was greater than on cotton or mungbean (Fig. 7b).

\section{DISCUSSION}

The flat profiles of infestation level and mean counts for SLW adults in the experimental cotton plots are validated by similarly flat profiles in both blocks of commercial cotton (cf. Figs 1a,c and 2a,c). By comparison, congruence in the profiles of nymphs from the experimental plots and Block 1 but not Block 2 (cf. Figs $1 b, d$ and 2b,d) can be explained on the basis of chronological age at sampling (days after planting). Cotton in the experimental plots at Time 2 was of the same chronological age ( 63 days) and stage (flowering) as that in Block 1 whereas the cotton in Block 2 was at or close to the cut-out stage when maximum vegetative growth was achieved. The relatively flat 
Table 1 Predicted leaf area index (LAI) and mean number of nodes for four crops at two sampling dates using the Agricultural Production Systems Simulator simulation model

\begin{tabular}{llcc}
\hline Sampling date & \multicolumn{1}{c}{ Crop } & Nodes $(\mathrm{max}, \mathrm{min})$ & $\mathrm{LAI}\left(\mathrm{m}^{2} \cdot \mathrm{m}^{-2}\right)$ \\
\hline $25 / 02 / 2003$ & Cotton & $8.7(11,7)$ & 0.27 \\
& Mungbean & $6.2(8,4)$ & 0.30 \\
& Soybean & $7.3(10,5)$ & 0.55 \\
$24 / 03 / 2003$ & Sunflower & $16.4(21,8)$ & 0.72 \\
& Cotton & $12.4(15,7)$ & 0.51 \\
& Mungbean & $11.7(13,7)$ & 1.41 \\
& Soybean & $12.2(15,7)$ & 1.86 \\
& Sunflower & $30.1(35,25)$ & 0.99 \\
\hline
\end{tabular}

profiles of nymphs in Block 2 reflect re-distribution from the lower to the upper leaf nodes in older cotton crops, a commonly observed distributional response to cessation of plant growth (Ohnesorge \& Rapp 1986; Naranjo \& Flint 1994).

Based on the distributional data for cotton, sampling for adults at nodes 3-5 and nymphs at nodes 7-10 from squaring to boll opening stages would meet the requirements of efficiency and practicality from a commercial sampling perspective. In cotton, this is at or past the stage where maximum vegetative growth has been achieved (cut-out), the older main stem leaves in the lower section of the crop canopy are harder to access in the field due to canopy closure and are generally of lower quality in terms of sustaining SLW activity. Thus, the lower section of the crop canopy, below node 10 , can effectively be ignored from a SLW sampling perspective.

Our proposed sampling approach for cotton was used by Sequeira and Naranjo (2008) to develop a fixed sample size, binomial sampling plan for SLW in Australian cotton and underpins the current industry recommendation (Cotton Pest
Management Guide 2017-2018) which specifies sampling SLW adults at nodes 3, 4 or 5 from squaring to boll opening stages. Validation studies conducted by the Commonwealth Scientific and Industrial Research Organisation on within-plant distributions of SLW in cotton crops grown in southern Queensland and northern New South Wales from 2015 to 2017 confirm the validity and applicability of the sampling approach presented here (Wilson LJ, unpublished data). Research is currently underway to expand the scope of the SLW sampling scheme for cotton developed by Sequeira and Naranjo (2008) to include a nymph sampling plan based on densities at nodes $7-10$, as proposed in this study.

The distributions of SLW adults and nymphs in experimental and validation mungbean plots (cf. Figs 3, 4) support the selection of nodes 2-3 as the optimal sampling location for adults and nodes 4-5 for nymphs, regardless of crop stage. In soybean (Fig. 5), adult sampling would be most effective at nodes 3-4 and nymph sampling at nodes 5-6 in all stages of soybean. By comparison, based on the vertical segregation of SLW adults and nymphs in sunflower (Fig. 6), the optimal sampling location for adults is in the middle of the upper canopy (nodes 5-7) and in the middle of the lower canopy (nodes 17-21) for nymphs.

The use of efficient and cost-effective methodology such as binomial sampling for estimating population abundance is another important consideration in the IPM decision-making process (Binns \& Bostanian 1990; Naranjo \& Flint 1995). The analysis of infestation level in this study serves to demonstrate the applicability of binomial sampling methodology to situations where the primary objective of the sampling is to classify field populations for the purpose of making pest management decisions (Binns \& Nyrop 1992).

Binomial sampling is underpinned by the relationship between the proportion infested, as determined by the use of an
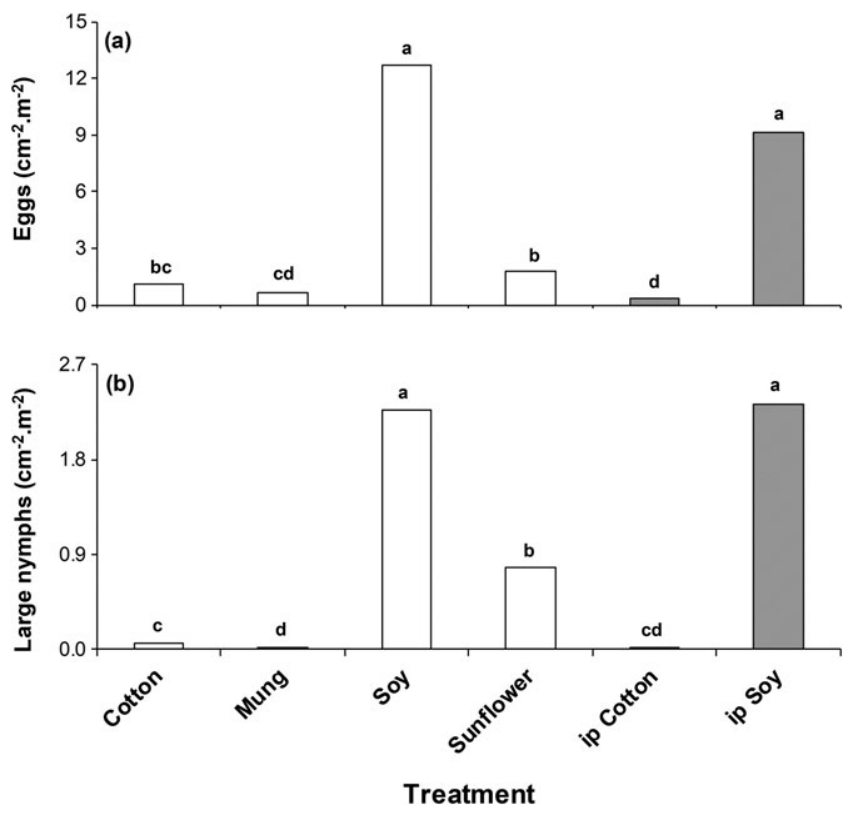

Fig. 7. Density of silverleaf whitefly (a) eggs and (b) nymphs on four crops in either monoculture (open bars) or interplant (ip, hatched bars) experimental layouts assessed at 66 days after planting, averaged across all main stem nodes and weighted by predicted values of the leaf area index. Bars with a common letter are not significantly different $(P>0.05)$. 
appropriate tally threshold, and the sample mean (Gerrard \& Chiang 1970; Wilson \& Room 1983; Binns and Bostanian, 1990; Jones 1994). In situations where SLW population density is low, simple presence/absence sampling (i.e. using a tally threshold of $\geq 1$ ) is sufficient whereas in moderate-high SLW density situations, higher thresholds can provide more information and greater accuracy (Jones 1994; Naranjo et al. 1996; Sequeira \& Naranjo 2008).

A limitation of the binomial method is that its accuracy in predicting the sample mean decreases as the proportion infested increases above 80\% (Gerrard \& Chiang 1970; Binns and Bostanian, 1990; Sanchez et al. 2002). This limitation can be overcome by increasing the tally threshold, i.e. the count above which the sample is considered infested (Sanchez et al. 2002). In the context of this study, the use of TT1 resulted in infestation levels $\geq 90 \%$ for SLW eggs on cotton (Fig. 1c), soybean (Fig. 5c) and sunflower (Fig. 6c); the use of TT2 gave a somewhat better result, with lower infestation levels, but one that could be further improved by the use of higher thresholds to quantify infestation level.

Our use of differences in SLW egg counts among leaf nodes to infer the distribution of adults can be justified on the basis of whitefly egg counts being typically higher on leaves with greater numbers of adults (van Lenteren \& Noldus 1990; Naik \& Lingappa 1992). More females choosing to lay eggs and/or females choosing to lay eggs for longer on particular leaves will result in higher egg densities on some leaves than on others. Thus, the relative distribution of SLW eggs among leaves is indicative of where the adults choose to spend a considerable proportion of their time and therefore reflects the likelihood of finding adults on a given leaf and nodal position.

LAI adjusted estimates of mean egg density indicate overwhelming ovipositional preference for soybean followed by sunflower, then cotton and least for mungbean (Fig. 7a). The ovipositional response strongly favouring soybean over cotton by a factor of 26 in the intercropped treatments where the inferred biomass of the former available for ovipositional activity was just 1.4 times that of the latter, is indicative of innate preference based on host plant characteristics other than just differences in green leaf area. Host plant preference hierarchies of SLW identified in this study and in others (e.g. Costa et al. 1991; Simmons 1994; Chu et al. 1995; Schuster 2003; AbdelBaky et al. 2004; Moore et al. 2004; Lee et al. 2009) may be of relevance in determining cropping options and sequences at the farm level and in trap cropping and other cultural tactics for pest population management in commercial cropping systems.

The density of nymphs is indicative of population growth potential. The differences in standardised density of nymphs among the four crops at Time 2 (Fig. $7 b$ ) reflect their relative importance as sources of SLW from an area-wide or cropping system perspective. A strong preference for soybean and susceptibility of the plant in early vegetative stages to SLW feeding injury (R. Sequeira, unpublished data) helps explain the decimation of the commercial soybean industry in central Queensland following the SLW outbreak of 2001 (Moore et al. 2004). In line with this study, density data from commercial sunflower crops (Sequeira et al. 2009) showed that sunflower can be a significant source of SLW although it does not exhibit visible signs of feeding damage, except in the very early (cotyledon) stages of plant establishment.

Surveys of SLW since 2004 have shown very low densities in commercial mungbean crops ( $\mathrm{R}$ Sequeira, unpublished data). This finding is consistent with the low preference for, and densities of, SLW in mungbean shown in this study and others (e.g. Abdel-Baky et al. 2004) and may explain the growth of the mungbean industry in SLW-endemic areas of Queensland. We attribute the oviposition activity on mungbean observed in this study partly to the aftermath of the 2001 SLW outbreak in the central Queensland region, centred in the Emerald irrigation area, which resulted in highly elevated base population densities on all crops and broadleaf vegetation in the following autumnwinter of 2002 and spring-summer of 2003 (Sequeira et al. 2009).

Despite being a relatively low quality host plant, the rising pest status of SLW on cotton in Australia (Sequeira \& Naranjo 2008; Sequeira et al. 2009) is undoubtedly a function of the large areas under cultivation in various parts of eastern Australia and other factors such as crop management practices. Thus, crop choice within cropping sequences or farm layouts will be an important determinant of SLW pest pressure at the individual cropping enterprise level with broader ramifications for areawide and regional population dynamics.

\section{ACKNOWLEDGEMENTS}

This research was funded by the Australian Cotton and Grains Research and Development corporations. We thank Andrew Moore and Alison Shields for their efforts in collecting the data and Howard Cox for assistance with APSIM modelling.

\section{REFERENCES}

Abdel-Baky NF, El-Naga AMA, El-Nagar ME \& Heikal GAM. 2004. Population density and host preference of the silverleaf whitefly, Bemisia argentifolii Perring \& Bellows, among three important summer crops. Egyptian Journal of Biological Pest Control 14, 251-258.

Arnó J, Albajes R \& Gabarra R. 2006. Within-plant distribution and sampling of single and mixed infestations of Bemisia tabaci and Trialeurodes vaporarioum (Homoptera: Aleyrodidae) in winter tomato crops. Journal of Economic Entomology 99, 331-340.

Binns MR \& Bostanian NJ. 1990. Robust binomial decision rules for integrated pest management based on the negative binomial distribution. American Entomologist 36, 50-54.

Binns MR \& Nyrop JP. 1992. Sampling insect populations for the purpose of IPM decision making. Annual Review of Entomology 37, 427-453.

Chen JM \& Black TA. 1991. Measuring leaf area index of plant canopies with branch architecture. Agricultural and Forest Meteorology 57, 1-12.

Chu CC, Henneberry TJ \& Cohen AC. 1995. Bemisia argentifolii (Homoptera: Aleyrodidae): host preference and factors affecting oviposition and feeding site preference. Environmental Entomology 24, 354-360

Costa HS, Brown JK \& Byrne DN. 1991. Host plant selection by the whitefly Bemisia tabaci (Gennadius) (Hemiptera: Aleyrodidae) under greenhouse conditions. Journal of Applied Entomology 112, 146-152.

Cotton Pest Management Guide 2017-2018. Cotton Research \& Development Corporation, Narrabri, NSW. [Accessed 12 Sept 2017.] Available from URL: http://www.crdc.com.au/publications/cotton-pest-management-guide 


\section{I2 R V Sequeira and D J Reid}

De Barro PJ. 1995. Bemisia tabaci biotype B: a review of its biology, distribution and control. Technical paper. CSIRO Division of Entomology Canberra, Australia; November Paper No.: 36, 58 pp.

De Barro PJ \& Coombs MC. 2009. Post-release evaluation of Eretmocerus hayati Zolnerowich \& Rose in Australia. Bulletin of Entomological Research 99, 193-206.

De Barro PJ, Liu SS, Boykin LM \& Dinsdale AB. 2011. Bemisia tabaci: a statement of species status. Annual Review of Entomology 56, 1-19.

Ellsworth PC \& Martinez-Carrillo JL. 2001. IPM for Bemisia tabaci: a case study from North America. Crop Protection 20, 853-869.

Gerling D \& Mayer RT, eds. 1996. Bemisia 1995: Taxonomy, Biology, Damage, Control and Management. Intercept, UK 702 pp.

Gerrard DJ \& Chiang CH. 1970. Density estimation of corn rootworm egg populations based upon frequency of occurrence. Ecology 51, 237-245.

Gunning RV, Byrne FJ, Condé BD, Connelly MI, Hergstrom K \& Devonshire AL. 1995. First report of B-biotype Bemisia tabaci (Gennadius) (Hemiptera: Aleyrodidae) in Australia. Journal of the Australian Entomological Society 34, 116.

Hou M, Lu W \& Wen J. 2007. Within-plant distribution of Bemisia tabaci (Homoptera: Aleyrodidae) adults and immatures on greenhouse-grown winter cucumber plants. Journal of Economic Entomology 100, 1160-1165.

Inbar M \& Gerling D. 2008. Plant-mediated interactions between whiteflies, herbivores, and natural enemies. Annual Review of Entomology 53, 431-448.

Jones VP. 1994. Sequential estimation and classification procedures for binomial counts. In: Handbook of Sampling Methods for Arthropods in Agriculture (eds LP Pedigo \& GD Buntin), pp. 175-206. CRC Press, New York.

Keating BA, Carberry PS, Hammer GL et al. 2003. An overview of APSIM, a model designed for farming systems. European Journal of Agronomy 18, 267-288.

Lee D, Nyrop JP \& Sanderson JP. 2009. Attraction of Trialeurodes vaporariorum and Bemisia argentifolii to eggplant, and its potential as a trap crop for whitefly management on greenhouse poinsettia. Entomologia Experimentalis et Applilcata 133, 105-116.

van Lenteren JC \& Noldus JPJJ. 1990. Whitefly-plant relationships: behavioural and ecological aspects. In: Whiteflies: Their Bionomics, Pest Status and Management (ed D Gerling), pp. 47-98. Intercept, Hanover.

Lynch RE \& Simmons AM. 1993. Distribution of immatures and monitoring of adults sweetpotato whitefly, Bemisia tabaci (Gennadius) (Homoptera: Aleyrodidae) in peanut, Arachis hypogaea. Environmental Entomology 22, 375-380.

Moore AD, Sequeira RV \& Woodger TA. 2004. Susceptibility of crop plants to Bemisia tabaci (Gennadius) B-biotype (Hemiptera: Aleyrodidae) in central Queensland, Australia. Australian Entomologist 31, 69-74.

Muniz M, Nombela G \& Barrios L. 2002. Within-plant distribution and infestation pattern of B- and Q-biotypes of the whitefly, Bemisia tabaci, on cotton and pepper. Entomologia Experimentalis et Applicata 104, 369-373.

Naik LK \& Lingappa S. 1992. Distribution pattern of Bemisia tabaci (Gennadius) in cotton plant. International Journal of Tropical Insect Science 13, 377-379.

Naranjo SE. 1996. Sampling Bemisia for research and pest management applications. In: Bemisia 1995: Taxonomy, Biology, Damage, Control and Management (eds D Gerling \& RT Mayer), pp. 209-224. Intercept, UK.

Naranjo SE \& Flint HM. 1994. Spatial distribution of preimaginal Bemisia tabaci (Homoptera: Aleyrodidae) in cotton and development of fixedprecision sequential sampling plans. Environmental Entomology 23, 254-266.

Naranjo SE \& Flint HM. 1995. Spatial distribution of adult Bemisia tabaci (Homoptera: Aleyrodidae) in cotton and development and validation of fixed-precision sampling plans for estimating population density. Environmental Entomology 24, 261-270.

Naranjo SE, Hollis MF \& Henneberry TJ. 1996. Binomial sampling plans for estimating and classifying population density of adult Bemisia tabaci in cotton. Entomologia Experimentalis et Applicata 80, 343-353.

Ohnesorge B \& Rapp G. 1986. Methods for estimating the density of whitefly nymphs (Bemisia tabaci Genn.) in cotton. Tropical Pest Management 32, 207-211.

Oliveira MRV, Henneberry TJ \& Anderson P. 2001. History, current status, and collaborative research projects for Bemisia tabaci. Crop Protection 20, 709-723.

Rao NV, Reddy AS, Rao BR \& Satyanarayana G. 1991. Intraplant distribution of whitefly, Bemisia tabaci Genn. on cotton, Gossypium hirsutum L. Journal of Insect Science 4, 32-36.

Ross J. 1981. The Radiation Regime and Architecture of Plant Stands. Dr W Junk Publishers, The Hague.

Schuster DJ. 1998. Intraplant distribution of immature life stages of Bemisia argentifolii (Homoptera: Aleyrodidae) on tomato. Environmental Entomology 27, 1-9.

Sanchez JA, McGregor RR \& Gillespie DR. 2002. Sampling plan for Dicyphus hesperus (Heteroptera: Miridae) on greenhouse tomatoes. Environmental Entomology 31, 331-338.

Schuster DJ. 2003. Preference of Bemisia argentifolii (Hemiptera: Aleyrodidae) for selected vegetable hosts relative to tomato. Journal of Agricultural and Urban Entomology 20, 59-67.

Sequeira RV \& Naranjo SE. 2008. Sampling and management of Bemisia tabaci (Genn.) biotype B in Australian cotton. Crop Protection 27, 1262-1268.

Sequeira RV, Shields A, Moore A \& De Barro P. 2009. Interseasonal population dynamics and pest status of Bemisia tabaci (Gennadius) biotype B in an Australian cropping system. Bulletin of Entomological Research 99, 325-335.

Simmons AM. 1994. Oviposition on vegetables by Bemisia tabaci (Homoptera: Aleyrodidae) temporal and leaf surface factors. Environmental Entomology 23, 381-389.

Tonhasca A, Palumbo JC Jr \& Byrne BN. 1994. Distribution patterns of Bemisia tabaci (Homoptera: Aleyrodidae) in cantaloupe fields in Arizona. Environmental Entomology 23, 949-954.

VSN International. GenStat for Windows, 13th edn., VSN International, Hemel Hempstead, UK. 2010. [Accessed 22 June 2017.] Available from URL: GenStat.co.uk

Wilson LT \& Room PM. 1983. Clumping patterns of fruit and arthropods in cotton with implications for binomial sampling. Environmental Entomology $12,50-54$.

Accepted for publication 21 September 2017. 